\title{
Correction to: Sublethal effects of a juvenile hormone analog, Pyriproxyfen demographic parameters of non-target predator, Hippodamia convergens Guerin-Meneville (Coleoptera: Coccinellidae)
}

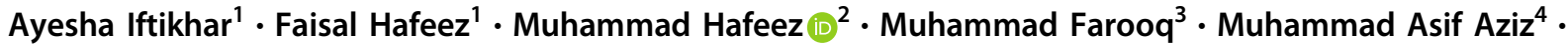 \\ Muhammad Sohaib ${ }^{5} \cdot$ Afifa Naeem ${ }^{1} \cdot$ Yaobin $\mathrm{Lu}^{2}$
}

Published online: 28 April 2020

(c) Springer Science+Business Media, LLC, part of Springer Nature 2020

Correction to: Ecotoxicology (2020)

https://doi.org/10.1007/s10646-020-02159-7

The original version of the article was inadvertently published with the errors in textual, equations, references, tables and figures. The corrected texts are given below:

In Data analysis section, the second equation should read as:

$T=\left(\ln R_{0}\right) / r$.

In the same section, the para should read as:

These authors contributed equally: Ayesha Iftikhar, Faisal Hafeez

The original article can be found online at https://doi.org/10.1007/ s10646-020-02159-7.

Ayesha Iftikhar

aishaiftkhr@yahoo.com

$\triangle$ Muhammad Hafeez

hafeez_203@yahoo.com

1 Entomological Research Institute, Ayub Agricultural Research Institute, Faisalabad, Pakistan

2 State Key Laboratory Breeding Base for Zhejiang Sustainable Pest and Disease Control, Zhejiang Academy of Agricultural Sciences, Institute of Plant Protection and Microbiology, Hangzhou 310021, PR China

3 School of Earth, Environment and Biological Sciences, Science and Engineering Faculty, Queensland University of Technology, Brisbane, QLD, Australia

4 Department of Entomology, Pir Mehr Ali Shah, Arid Agriculture University Rawalpindi, Rawalpindi, Pakistan

5 Institute of Agricultural Sciences, University of the Punjab, Lahore, Pakistan
In addition to life table parameters, age-stage specific survival rate $s_{x j}$ (where, $x=$ age and $j=$ stage), age specific fecundity $m_{x}$, age-stage specific fecundity $f_{x j}$, age specific maternity $l_{x} m_{\mathrm{x}}$, age-stage specific life expectancy $e_{x j}$ (Chi and $\mathrm{Su}$ 2006), age-stage specific reproductive value $v_{x j}$ (Tuan et al. 2014a, b), APOP (adult pre-ovipositional period), and TPOP (total pre-ovipositional period), for all treatments were analyzed by a computer software TWOSEX-MSChart (Chi 2018) based on age-stage, two sex life table theory (Chi 1988; Chi and Liu 1985). Variances and standard errors were assessed using bootstrap (100,000 replicates) (Efron and Tibshirani 1993).

In Table 2, the legend should read as, "Standard errors were estimated by using bootstrap technique with 100,000 resampling. Differences between sexes were compared with paired bootstrap test. Means followed by a different letter indicate significant difference between treatments $(P<$ 0.05)."

Table 3 legend should read as, "Standard errors were estimated by using bootstrap technique with 100,000 resampling. Differences between sexes were compared with paired bootstrap test. Means followed by a different letter indicate significant difference between treatments $(P<$ 0.05). TPOP Total pre-oviposition period; $A P O P$ Adult preoviposition period."

Legend of Table 4 should read as, "Standard errors were estimated by using bootstrap technique with 100,000 resampling. Means followed by a different letter indicate significant difference between treatments $(P<0.05) . T=$ Mean generation time; $R_{0}=$ Net reproductive rate: $r=$ Intrinsic rate of increase: $\lambda=$ Finite rate of increase."

The corrected Figs. 3 and 4 are given below:

The original article has been corrected. 

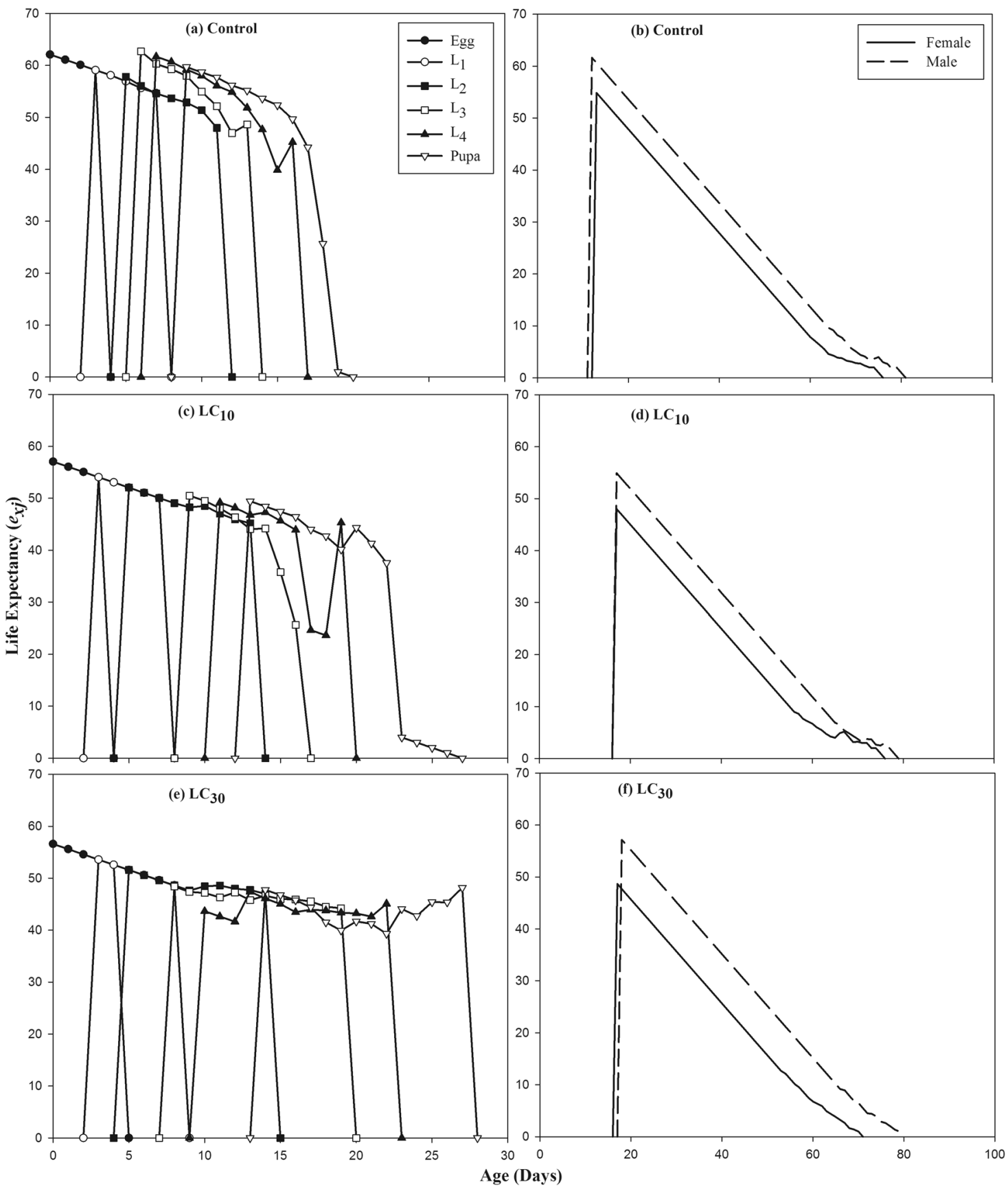

Fig. 3 a-f Sublethal effects of pyriproxyfen on life expectancy (exj) of $H$. convergens 

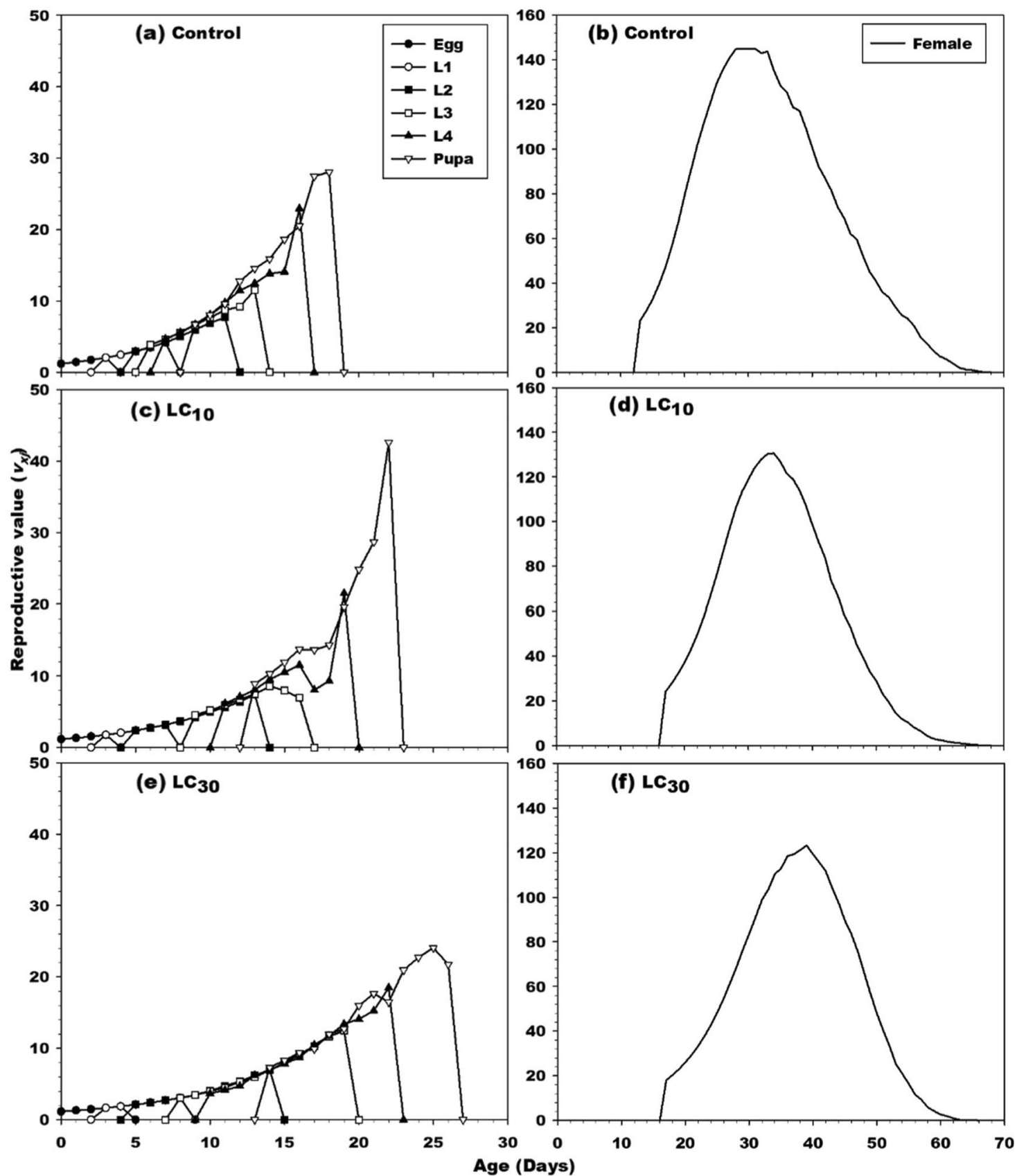

Fig. 4 a-f Sublethal effects of pyriproxyfen on reproductive value $\left(v_{x j}\right)$ of $H$. convergens

\section{References}

Chi H, Su HY (2006) Age-stage, two-sex life tables of Aphidius gifuensis (Ashmead)(Hymenoptera: Braconidae) and its host Myzus persicae (Sulzer)(Homoptera: Aphididae) with mathematical proof of the relationship between female fecundity and the net reproductive rate. Environ Entomol $35: 10-21$
Tuan SJ, Lee CC, Chi H (2014a) Population and damage projection of Spodoptera litura (F.) on peanuts (Arachis hypogaea L.) under different conditions using the age-stage, two-sex life table. Pest Mgt Sci 70:805-813

Tuan SJ, Lee CC, Chi H (2014b) Erratum Population and damage projection of Spodoptera litura (F.) on peanuts (Arachis hypogaea L.) under different conditions using the age-stage, two-sex life table. Pest Mgt Sci 70:1936 